\title{
The association between Histone 3 Lysine 27 Trimethylation (H3K27me3) and prostate cancer: relationship with clinicopathological parameters
}

Marjolaine Ngollo ${ }^{1,2}$, Andre Lebert ${ }^{3}$, Aslihan Dagdemir ${ }^{1,2}$, Gaelle Judes ${ }^{1,2}$, Seher Karsli-Ceppioglu ${ }^{1,2}$, Marine Daures ${ }^{1,2}$, Jean-Louis Kemeny ${ }^{4}$, Frederique Penault-Llorca ${ }^{1,2}$, Jean-Paul Boiteux ${ }^{5}$, Yves-Jean Bignon ${ }^{1,2^{*}}$, Laurent Guy ${ }^{2,5}$ and Dominique Bernard-Gallon ${ }^{1,2}$

\begin{abstract}
Background: It is well established that genetic and epigenetic alterations are common events in prostate cancer, which may lead to aberrant expression of critical genes. The importance of epigenetic mechanisms in prostate cancer carcinogenesis is increasingly evident. In this study, the focus will be on histone modifications and the primary objectives are to map H3K27me3 marks and quantify RAR beta 2, ER alpha, SRC3, RGMA, PGR, and EZH2 gene expressions in prostate cancer tissues compared to normal tissues. In addition, a data analysis was made in connection with the clinicopathological parameters.
\end{abstract}

Methods: 71 normal specimens and 66 cancer prostate tissues were randomly selected in order to assess the proportion of the repressive H3K27me3 mark and gene expression. H3K27me3 level was evaluated by ChIP-qPCR and mRNA expression using RT-qPCR between prostate cancer and normal tissues. Subsequently, western-blotting was performed for protein detection. The analysis of variance (ANOVA) was performed, and Tukey's test was used to correct for multiple comparisons ( $p$-value threshold of 0.05 ). The principal component analysis (PCA) and discriminant factorial analysis (DFA) were used to explore the association between H3K27me3 level and clinicopathological parameters.

Results: The study demonstrated that H3K27me3 level was significantly enriched at the RAR beta 2, ER alpha, PGR, and RGMA promoter regions in prostate cancer tissues compared to normal tissues. After stratification by clinicopathological parameters, the H3K27me3 level was positively correlated with Gleason score, PSA levels and clinical stages for RAR beta 2, ER alpha, PGR, and RGMA. High H3K27me3 mark was significantly associated with decreased RAR beta 2, ER alpha, $P G R$ and RGMA gene expressions in prostate cancer sample compared to the normal one. Moreover, the results showed that mRNA level of $E Z H 2$, AR and SRC3 are upregulated in prostate cancer compared to normal prostate tissues and this correlates positively with Gleason score, PSA levels and clinical stages. Obviously, these observations were confirmed by protein level using western-blot.

Conclusions: This data clearly demonstrated that H3K27me3 level correlated with aggressive tumor features. Also this study revealed that reverse correlation of RAR beta 2, ER alpha, $P G R$, and RGMA expressions with EZH2, SRC3, and $A R$ expressions in prostate cancer tissues suggests that these genes are the target of $\mathrm{EZH} 2$. Therefore, all therapeutic strategies leading to histone demethylation with epigenetic drugs such as histone methyltransferase inhibitor may be relevant treatments against prostate cancer.

Keywords: Chromatin immunoprecipitation, Epigenetic, Prostate cancer, Histone modifications, Trimethylation

\footnotetext{
* Correspondence: Yves-Jean.BIGNON@cjp.fr

'Department of Oncogenetics, Centre Jean Perrin, CBRV, 28 place Henri

Dunant, BP 38, 63001 Clermont-Ferrand, France

2EA 4677 "ERTICA", University of Auvergne, 28 place Henri Dunant, BP 38,

63001 Clermont-Ferrand, France

Full list of author information is available at the end of the article
}

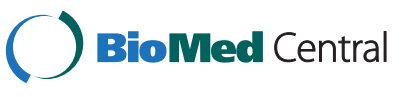

(c) 2014 Ngollo et al.; licensee BioMed Central. This is an Open Access article distributed under the terms of the Creative Commons Attribution License (http://creativecommons.org/licenses/by/4.0), which permits unrestricted use, distribution, and reproduction in any medium, provided the original work is properly credited. The Creative Commons Public Domain Dedication waiver (http://creativecommons.org/publicdomain/zero/1.0/) applies to the data made available in this article, unless otherwise stated. 


\section{Background}

Prostate cancer is the most frequently diagnosed cancer in men in the western world and second leading cause of cancer death in males worldwide [1]. In 2011, prostate cancer represented 71,200 new cases and 8,700 deaths in France. Prostate cancer like many other malignancies arises from progressive genetic and epigenetic alterations [2]. Tumorigenesis and progression of prostate cancer result from the accumulation of genetic and epigenetic alterations. Epigenetic modifications include several different phenomena, such as DNA methylation [3], histone modifications [4], and microRNAs (miR) regulation [5]. Basically, epigenetics regulate gene expression and play an important role in carcinogenesis [6].

In this study, the focus is put on histone modifications and their role in prostate cancer progression. Studies have shown that histone modifications contribute to the onset and progression of prostate cancer [7]. Common histone modifications leading to gene silencing in prostate cancer include histone H3 lysine 9 methylation (H3K9me3), histone deacetylation, and polycomb-based histone $\mathrm{H} 3$ lysine 27 trimethylation (H3K27me3) [8]. Polycomb-mediated H3K27me3 has been shown to play critical role in diverse biological processes, such as development, stem cell maintenance, transcriptional silencing of homeotic gene, and in early steps of X-chromosome inactivation in women [9].

So far, it is important to understand the role of histone modifications in the control of gene transcription. H3K $27 \mathrm{me} 3$ is catalyzed by the polycomb enhancer of zeste homolog 2 (EZH2), the catalytic core protein of the polycomb repressor complex 2 (PRC2). This histone methyltransferase is well known in initiating target gene silencing by promoting $\mathrm{H} 3 \mathrm{~K} 27 \mathrm{me} 3$ leading to the chromatin condensation [10]. Many authors have demonstrated that overexpression of EZH2 was strongly associated with progression and invasion of prostate cancer [11]. In addition, some studies showed that $E Z H 2$ is upregulated by aberrant expression of MYC transcription factor and microRNA [12]. Clearly, MYC promotes EZH2 expression by repressing the expression of $m i R-26 a$ and $m i R-26 b$, which might be a negative regulator of $E Z H 2$ [13].

Kondo et al. (2008) found that up to $5 \%$ of promoters were enriched with H3K27me3 and showed none or low DNA methylation in their promoters. This data establish EZH2-mediated H3K27me3 like a mechanism of gene silencing in cancer potentially independent of DNA methylation [8].

In fact, to study histone methylation, a selection of six genes involved in prostate cancer was made, including RAR beta 2, ER alpha, PGR, RGMA, EZH2, and SRC3.

The retinoic acid receptor (RAR) is a transcription factor that regulates transcription of set genes involved in biological processes such as apoptosis, proliferation and cellular differentiation. Of course, RAR beta 2 is one of the genes involved in aberrant methylation in human prostate cancer $[14,15]$. Previous studies reported that the methylated promoter region of RAR beta 2 in prostate cancer cell lines (LNCaP and PC3) was associated with both hypoacetylation and hypermethylation of histone $\mathrm{H} 3$ [9]. However, few studies knew about the mechanisms underlying the involvement of histone methylation upon the silencing of RAR beta 2 expression in tumor cells, until Moisson et al. (2013) confirmed that DNA hypermethylation cannot explain by itself the epigenetic repression of RAR beta 2 gene [15].

Truly, prostate cancer accelerates the osteoblastic differentiation during the process of metastasis interacting with bone mophogenetic proteins (BMPs) [16]. Recently, repulsive guidance molecule A (RGMA) a GPI-linked membrane protein has been identified as co-receptor of bone morphogenetic proteins (BMPs) [17]. Kondo et al. (2008) demonstrated that, RGMA expression was significantly lower in cancer tissues than in normal ones. However, the underlying mechanisms are not well understood yet [8].

Also, it is well established that androgen receptor (AR) plays a critical role in prostate cancer cell proliferation, survival, and differentiation. But, some reports also dealt with the potential implication of other two steroid hormone nuclear receptors, estrogen receptor (ER) alpha and progesterone receptor (PGR) in prostatic carcinogenesis [18]. In any case, in the normal human prostate, immunohistochemical studies have revealed a stromal localization of ER alpha and PGR, and less or no ER alpha expression was detected in malignant prostate epithelium in various prostates [19]. PGR is the major ER alpha responsive gene, its expression is not detected in malignant prostatic epithelium [18].

Finally, steroid receptor coactivator 3 (SRC3) is a member of the p160 family of coactivators for nuclear hormone receptors including the androgen receptor. For instance, previous studies have shown that $S R C 3$ is overexpressed in prostate cancer cells and its overexpression correlates with prostate cancer proliferation and is inversely correlated with apoptosis [20].

The aim of this study was to assess the association between H3K27me3 level and prostate cancer risk and the correlation of H3K27me3 on EZH2, RAR beta 2, ER alpha, $P G R$, and $R G M A$ promoters with clinicopathological variables including Gleason score, PSA levels and clinical stages. Therefore, normalizing H3K27me3 by targeting inhibition of EZH2 seems to become a potential new method for cancer therapy.

\section{Results}

H3K27me3 correlated positively with clinicopathological parameters

Firstly, using ChIP assay, we demonstrated that H3K 27me3 occupancy at RAR beta 2, ER alpha, PGR, and 
RGMA promoters is increased in tumoral tissue compared to normal tissue unlike to $E Z H 2$ promoter. We did not find obvious H3K27me3 modification signals at the $S R C 3$ promoter (Figure 1). These results suggest that EZH2 regulates RAR beta 2, ER alpha, PGR and RGMA. On the contrary, SRC3 expression would be regulated in an H3K27me3-independent manner. The H3K27me3 level in tumoral and normal tissues was then explored by principal component analysis (PCA) to assess the relationship between Gleason score, PSA levels, and clinical stages. Additionally, the extracted PCA factors were used to examine the ability to discriminate between patients with cancer and healthy patients. PCA showed that the total variance explained by the first principal component (Dim1) of PCA was $61.26 \%$ whereas the second principal component (Dim2) of PCA explained nearly $19.67 \%$ of the total variance. As shown in Figure 2, on the first principal component, a clear discrimination can be seen between EZH2 gene and RAR beta 2, ER alpha, PGR and RGMA genes. SRC3 is orthogonal to the horizontal axis and therefore did not participate to PCA analysis. PCA results demonstrated a close relationship between H3K27me3 level and Gleason score, PSA levels and clinical stages. This means that, patients with a high proportion of H3K27me3 marks on RAR beta 2, ER alpha, $P G R$ and $R G M A$ genes have a high Gleason score and advanced clinical stage.

In a second step, discriminant factorial analysis (DFA) was applied to the PCA data that take into account the information contained in the raw data sets. DFA has allowed classifying patients according to different groups. For that purpose, patients in the study cohort were divided into two groups, $75 \%$ of patients have formed learning group and $25 \%$ validation group (Table 1 ). It has been noted that although Gleason score, PSA levels and clinical stages variables displayed high correlation, only the Gleason score was able to distinguish the three groups $(\mathrm{N}, \mathrm{GS} \leq 7$ and GS > 7) with a significant percentage of around $99 \%$. All patients are correctly classified, only 1 out of 48 patients was misclassified (Table 2). On the validation group, patients were $100 \%$ correctly classified (Table 3 ). The graphical representation of patients was described in
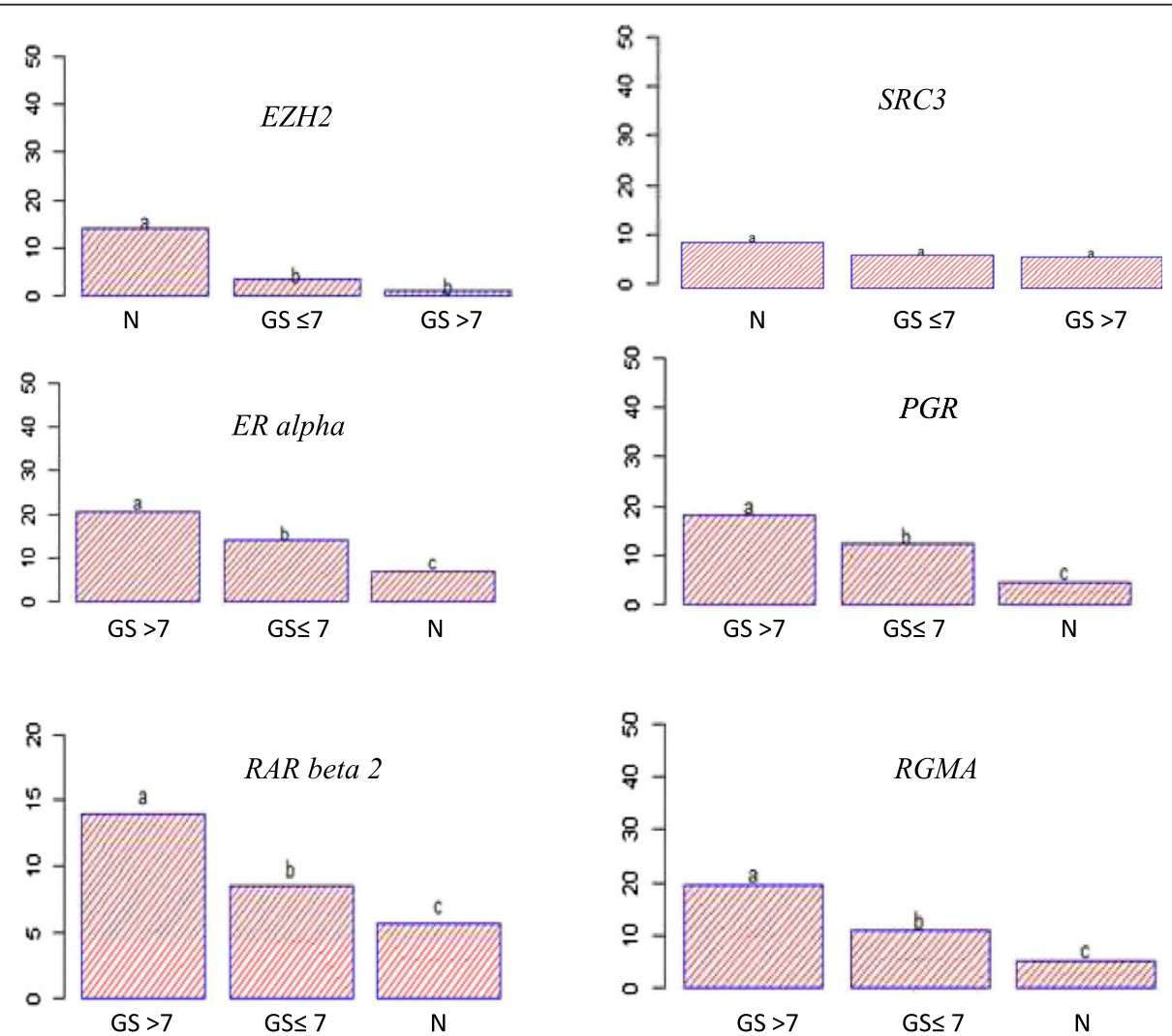

Figure 1 Assessment of H3K27me3 marks in normal and tumoral tissues using ChIP-qPCR. ChIP analysis indicates the change of H3K27me3 marks at six gene loci in prostate cancer tissues. H3K27me3 level on EZH2 was found to be lower in prostate cancer tissues $(n=32)$ versus normal tissues $(n=33)$. Contrariwise, the H3K27me3 level of RAR beta 2, PGR, ER alpha and RGMA was significantly higher in tumoral tissues that in normal tissues. The H3K27me3 level on SRC3 in cancer tissue did not reach statistical significance compared in normal tissue. The data is expressed as \% of input. Analysis of variance, followed by a Tukey multiple comparison test, was used for statistical analysis. The statistical significant between groups was indicated by letters "a", "b" and "c". ( $N=$ normal; $G S=$ Gleason score). 


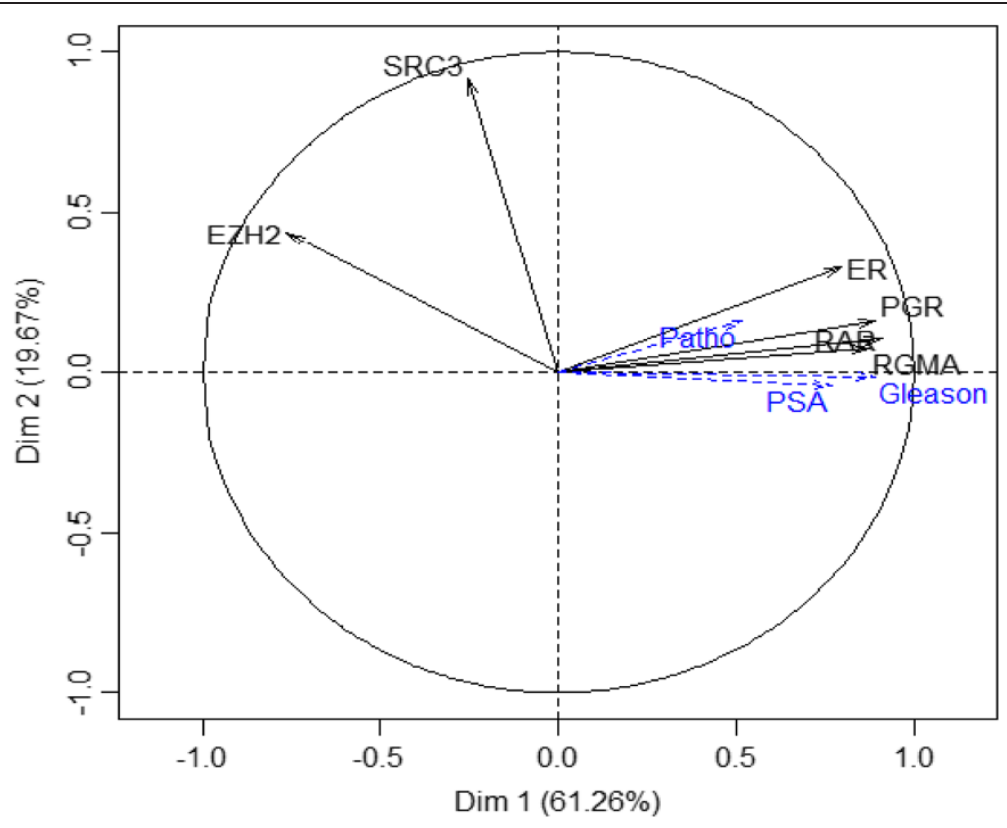

Figure 2 Principal component analysis (PCA) carried out to explore the relationships between H3K27 levels and clinicopathological parameters. H3K27me3 level was evaluated by PCA analysis. H3K27me3 levels on ER alpha, RAR beta 2, RGMA and PGR genes correlated positively with PSA level (PSA), clinical stage (patho) and Gleason score (Gleason).

Figure 3 and a clear discrimination between N, GS $\leq 7$ and GS $>7$ groups were observed. The same process was applied to clinical stages data. Regarding T1 clinical stage group, correct classification amounting to $80 \%$ was observed. Nevertheless, T2 clinical stage group was only $67 \%$ correctly classified. The T3 clinical stage group was not analyzed because we have only one patient in this group. None of the three groups (T1, T2 and T3 clinical stage) was $100 \%$ correctly classified, the classification rate was not satisfactory. However, with PSA levels, it was not possible to predict the membership of different groups established relative to H3K27me3 level.

\section{Gene expression in prostate tissues}

Two separate epigenetic pathways have been shown to be dysregulated or impaired in cancer. The first is the well-known silencing of genes by DNA methylation and the second is the silencing of genes mediated by the Polycomb repressor complex 2, which is often independent of DNA methylation. Thus, to demonstrate the role of

Table 1 Distribution of patients in two groups

\begin{tabular}{cccc}
\hline & Learning group & Validation group & Total \\
\hline Normal & 25 & 8 & 33 \\
Gleason score $\leq 7$ & 16 & 3 & 19 \\
Gleason score $>7$ & 7 & 5 & 12 \\
Total & 48 & 16 & 64 \\
\hline
\end{tabular}

$75 \%$ of patients allowed establishing learning database and $25 \%$ validation database.
H3K27me3 mark on gene silencing, we measured $R A R$ beta 2, ER alpha, PRG, RGMA, SRC3, AR, and EZH2 mRNA expressions from prostate tissues using RT-qPCR. Figure 4 depicts the relative mRNA expression and statistical analysis showed significantly higher $E Z H 2, A R$ and $S R C 3$ mRNA levels in patients with prostate cancer compared to normal patients. Contrary, RAR beta 2, ER alpha, $P G R$, and RGMA mRNA levels were decreased in prostate cancer tissue compared to normal one. Next, the analysis of gene expression was made by principal component analysis (PCA) to find a relationship with clinical pathological parameters. The first two principal components accounted for $68.31 \%$ of the total variance and explained the contrast between overexpressed genes $(A R, S R C 3$ and $E Z H 2)$ and underexpressed genes (RAR beta 2, ER alpha, PGR and $R G M A$ ). Additional variables (Gleason score, PSA levels and clinical stages) positively correlated with the overexpression of $E Z H 2, S R C 3$, and $A R$ therefore with the under expression of RAR beta 2, ER alpha, PRG and RGMA (Figure 5). Using DFA analysis, only the variable Gleason score allowed to properly classify and predict patients belonging to different groups (GS $\leq 7$ and $G S>7$ ). On the other hand, PSA levels and clinical stages did not help establish the separation into different groups.

To determine whether the gene expression data identified by mRNAs analysis resulted in biologically meaningful changes in protein expression, EZH2, RAR beta 2, ER alpha, PGR, RGMA, SRC3, and AR protein levels were assessed in prostate tissue samples using western blot analysis. As shown in Figure 6, the level of EZH2, SRC3 
Table 2 Classification of patients with different groups (normal, Gleason score $\leq 7$ and Gleason score $>7$ )

\begin{tabular}{cccccc}
\hline Observed patients & Predicted patients & Normal & Gleason score $\leq \mathbf{7}$ & Gleason score $>\mathbf{7}$ & \% of correct classification \\
\hline Normal $(n=25)$ & $\mathbf{2 5}$ & 0 & 0 & 100 \\
Score $\leq 7(n=16)$ & 0 & $\mathbf{1 6}$ & 0 & 100 \\
Score $>7(n=7)$ & 0 & 1 & 6 & 85.8 \\
Total & 25 & 17 & 6 & \\
\hline
\end{tabular}

This table represents a learning group and represents $75 \%$ of patients. The percentage of correctly classified patients corresponds to the ratio of the number of patients well classified by the total number of patients $(\mathrm{n})$. It is observed that there is one individual of Gleason score $>7$ group is misclassified. The number in bold corresponded to patients well classified.

and AR proteins were higher in prostate cancer tissues with a Gleason score of at least 8. On the contrary, RAR beta 2, ER alpha, PGR, RGMA protein levels were notably reduced in prostate cancer tissues compared to normal tissues. These results are consistent with the mRNA expression levels data.

\section{Effect of DZNep and SAHA on cell viability}

To further determinate cell viability, we treated DU145, PC3 and LNCaP cells with 3-deazaneplanocin A (DZNep) and suberoylanilide hydroxamic acid (SAHA) using various concentrations for $24 \mathrm{~h}, 48 \mathrm{~h}$ and $72 \mathrm{~h}$ and then, the number of viable cells was counted. As shown in Figure 7, DZNep significantly decreased the cell proliferation in a concentration-dependent manner. DZNep displayed an IC50 value of $8.97 \mu \mathrm{M}$ for DU145 against $10.76 \mu \mathrm{M}$ for PC3 and $9.01 \mu \mathrm{M}$ for $\mathrm{LNCaP}$ at $72 \mathrm{~h}$ of treatment. However, SAHA displayed an IC50 value of $2.05 \mu \mathrm{M}$ for DU145, $1.88 \mu \mathrm{M}$ for PC3 and 1.99 for LNCaP at $72 \mathrm{~h}$ of treatment. According to these results, $10 \mu \mathrm{M}$ DZNep and $2 \mu \mathrm{M}$ SAHA were chosen for mRNA experiments.

\section{Restoration of mRNA expression by DZNep and SAHA in prostate cancer cells}

To assess the effect of DZNep and SAHA, the levels of RAR beta 2, ER alpha, PRG, RGMA, SRC3, AR and $E Z H 2$ mRNA were examined in prostate cancer cells using RT-qPCR. As shown in Figure 8, after $72 \mathrm{~h}$ of treatment, DZNep was able to decrease EZH2 mRNA expression in LNCaP, PC3 and DU145 cells compared with control cells treated with DMSO 0.1\% ( $<<0.05)$. In the three cell lines, after $72 \mathrm{~h}, \mathrm{DZNep}$ induced an increase of RGMA and RAR beta 2 mRNA levels. This reexpression was associated with an $E Z H 2$ decreased. In both AR-negative cell lines, only PC3 cells reactive $A R$ expression after treatment with DZNep and SAHA. Any effect of DZNep on SRC3 expression has been observed on prostate cancer cell lines. However, in LNCaP, DU145 and PC3 cells there was a moderate increase of SRC3 expression after $72 \mathrm{~h}$ of treatment with SAHA. ER alpha and PGR expressions in DU145 and PC3 cells were undetected by RT-qPCR in control cells. However, in these two cell lines, ER alpha and $P G R$ re-expressions were detected with DZNep or SAHA treatment (Figure 8).

\section{Discussion}

The progression of prostate cancer, like other cancers, is facilitated by the epigenetic silencing of tumor-suppressor genes [21]. DNA hypermethylation in prostate cancer has been extensively studied [22,23]. However, histone modification patterns have been found to predict the risk of prostate cancer [24].

The present study clearly pointed out H3K27me3 as an epigenetic mark involved in the silencing of RAR beta 2, ER alpha, PGR, and RGMA genes in prostate cancer. Similarly, one of our previous studies showed that H3K27me3 marks were also significantly higher in peritumoral tissues from prostate cancer patients compared to normal tissue. These results suggest that peri-tumoral tissues seem to present molecular features such as tumoral tissues and established H3K27me3 like an epigenetic mark pathogenically involved in neoplasia trough the silencing of genes [25]. Previous study has also demonstrated an increase of RAR beta 2 and Adenomatous polyposis coli $(A P C)$ DNA methylation level in prostate tissue containing intraepithelial neoplasia and in adjacent non-neoplastic tissue [26].

Table 3 Classification of patients with different groups (normal, Gleason score $\leq 7$ and Gleason score $>7$ )

\begin{tabular}{|c|c|c|c|c|c|}
\hline Observed patients & Predicted patients & Normal & Gleason score $\leq 7$ & Gleason score $>7$ & $\%$ of correct classification \\
\hline Normal $(n=8)$ & & 8 & 0 & 0 & 100 \\
\hline Score $\leq 7(n=3)$ & & 0 & 3 & 0 & 100 \\
\hline Score $>7(n=5)$ & & 0 & 0 & 5 & 100 \\
\hline Total & & 8 & 3 & 5 & \\
\hline
\end{tabular}

This table represents a validation group and represents $25 \%$ of the patients. The percentage of correctly classified patients corresponds to the ratio of the number of patients well classified by the total number of patients (n). We observed that all patients are well classified. 


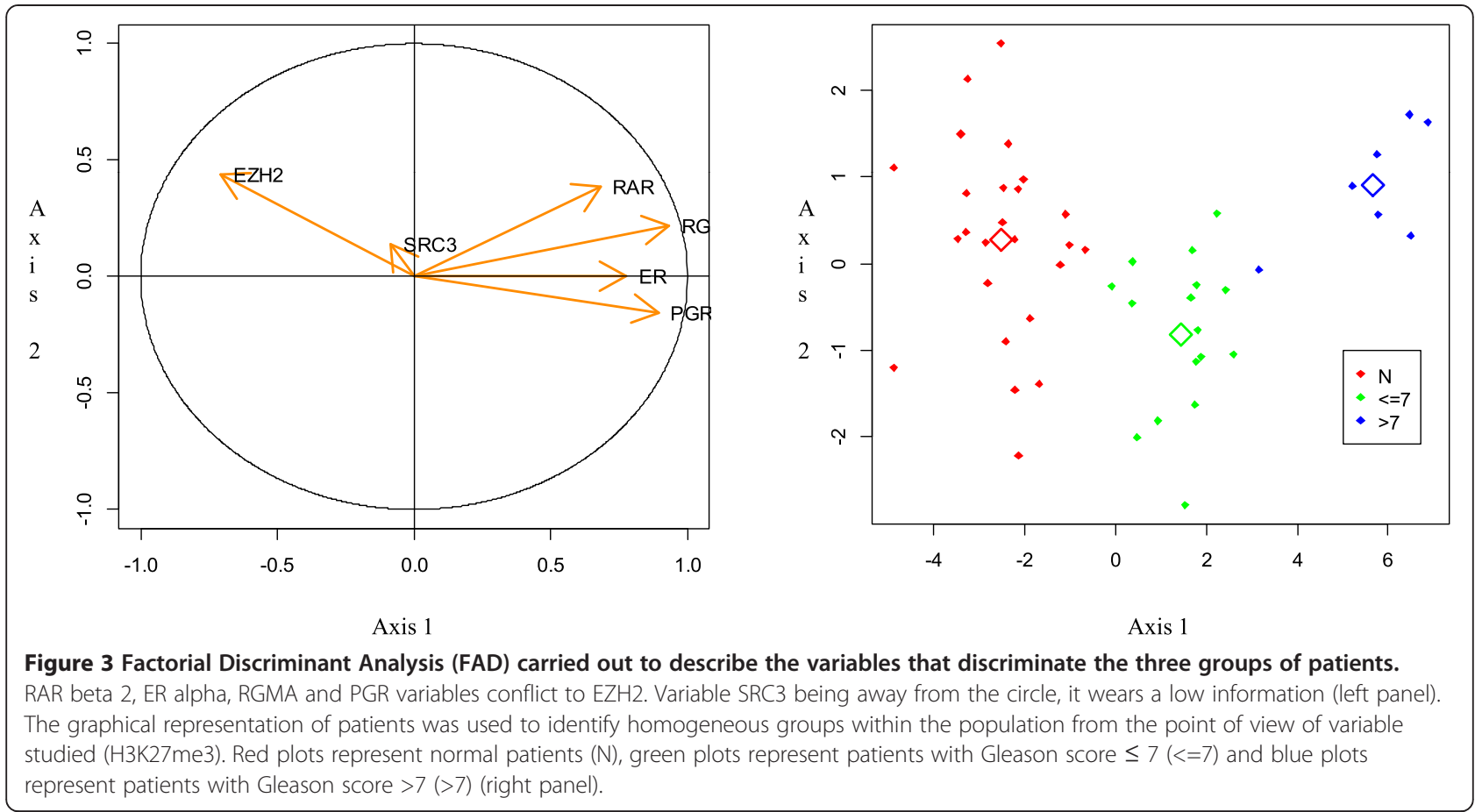

The PCA analysis was used and enabled us to show the existing correlation between all the different analyzed variables. Additionally, the DFA analysis was used because different groups were known and also to help predict group membership. This enables to include many variables in the study in order to determine the ones that discriminated between groups. The results showed an evident correlation between H3K27me3 level and clinicopathological parameters in prostate cancer tissues. However, it should be clearly noted that, if the overall average of the variables is significantly different between cancer and normal tissue, it does not mean that this variable discriminates different assigned classes. Obviously, results showed that only Gleason score variable is the best predictor of the clinicopathological parameters which classify patients into each group according to H3K27me3 level.

The PSA levels and clinical stages allowed separating normal patients with prostate cancer patients, without distinguishing different classes of clinical stages and PSA levels. About the clinical stages, DFA analysis did not help discriminate $\mathrm{T} 1$ and $\mathrm{T} 2$ clinical stage groups. Moreover patients with high level of H3K27 marks do not necessarily have high PSA level.

To examine the correlation between the abundance of H3K27me3 and gene activity, mRNA transcript levels were quantified using RT-qPCR. Previous studies have identified EZH2 as upregulated in prostate cancer [27,28]. Our results exhibited that, the group of patients with Gleason score $>7$ showed strong overexpression of $E Z H 2$, $A R$, and $S R C 3$ and eventually underexpression of $R A R$ beta 2, ER alpha, PRG, and RGMA compared to normal patients group. The group with Gleason score $\leq 7$ is intermediate between the two others. These results are in agreement with previous studies which showed an increase of $E Z H 2$ in prostate cancer relatively to normal tissue. Similarly, the results demonstrated that AR was also increased in prostate cancer tissue. Indeed, $A R$ is a potent oncogene which plays a crucial role in the early development of prostate cancer, as well as in metastatic castration-resistant progression in prostate cancer. Previous studies also showed that $A R$ expression was tumor stage-dependent [29]. SCR3 has also been identified as a key factor in the development of prostate cancer and there is an upregulation of $S R C 3$ in prostate cancer tissues. In fact, when AR was activated by hormones, AR bound to DNA in the nucleus cell and regulated gene expression through coactivators such as SRC3.

The identification of ER in the prostate gland was an indicator suggesting that locally produced testosterone metabolites with estrogenic activity may serve to balance the androgenic action in this tissue [30]. The data demonstrated a decrease in ER alpha expression in patients with Gleason score $>7$. This result indicated that, the estrogens via their ER alpha might inhibit growth of prostate cancer cells. Previously, we demonstrated that patients with Gleason score at 6 revealed no significant difference in the expression of ER alpha compared with the normal tissues [31]. However in this study, a positive correlation was observed between decreased ER alpha expression and tumor aggressiveness. 


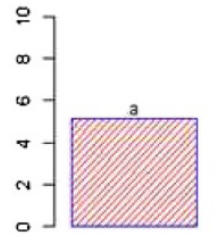

GS >7

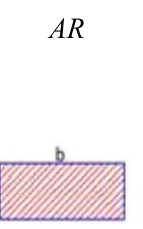

$\mathrm{GS} \leq 7$

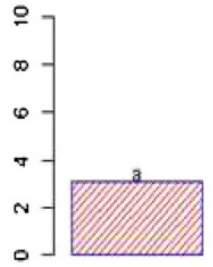

$\mathrm{GS}>7$

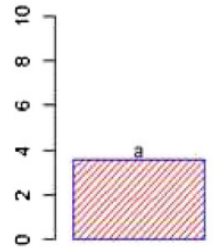

$\mathrm{N}$

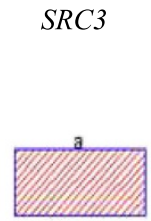

$\mathrm{GS} \leq 7$

$R A R$ beta 2

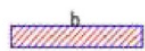

$\mathrm{GS} \leq 7$

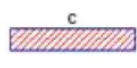

N

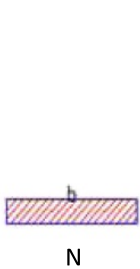

$\mathrm{N}$

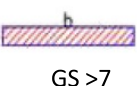

$R G M A$

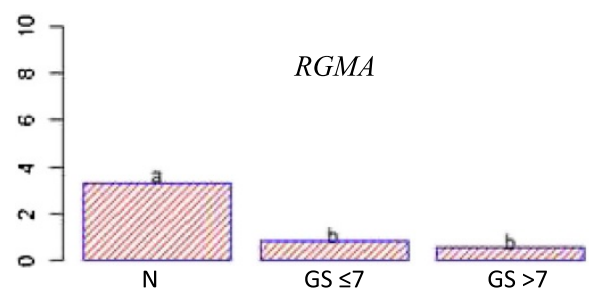

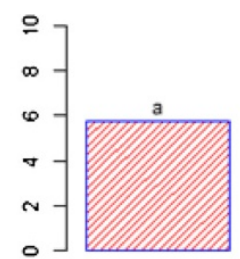

GS >7

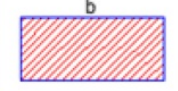

$\mathrm{GS} \leq 7$

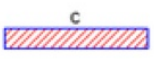

$\mathrm{N}$

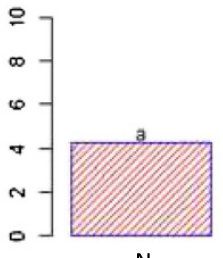

ER alpha

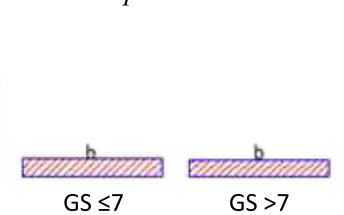

으

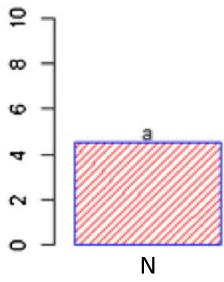

PGR

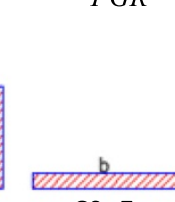

$\mathrm{GS} \leq 7$

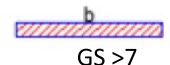

Figure $4 E Z H 2, A R$ and $S R C 3$ is upregulated in prostate cancer and inversely correlated with $R A R$ beta 2, ER alpha, PGR and $R G M A$. mRNA expression of seven genes were measured using RT-qPCR in normal tissues $(n=38)$ and cancerous tissues ( $n=34)$. 18S RNA was used as an internal control in PCR reactions. All genes that have high H3K27me3 levels in their promoter are consistent with the low mRNA expression levels. In contrast, genes that have low H3K27me3 levels are consistent with high mRNA expression levels. Analysis of variance, followed by a Tukey multiple comparison test, was used for statistical analysis. The statistical significant between groups was indicated by letters "a", "b" and " $\mathrm{c}$ ". ( $\mathrm{N}=$ normal; $\mathrm{GS}=$ Gleason score).

Unfortunately, very few studies have focused on the role of RGMA in prostate cancer. Li et al. (2012) observed that RGM proteins played inhibitor role in prostate cancer by suppressing cell growth, adhesion migration, and invasion [17]. In a comparative way, our studies showed that RGMA expression was down-regulated in most of the prostate cancer tissues and was positively correlated with Gleason score. On the other hand, another study showed similar findings in colon cancer [32].

Another key point is the fact that inactivation of tumor suppressor genes was a major contributing alteration factor in the initiation or progression of cancer. Like tumor suppressor genes, RAR beta 2 was recurrently silenced in prostate cancer, predominantly by epigenetic mechanisms. Again, previous studies showed that promoter region of RAR beta 2 was hypermethylated in more than $80 \%$ of human prostate cancer samples and prostate cancer cells leading to loss of $R A R$ beta 2 expression [15,33]. A clear relationship was proven between decreased of $R A R$ beta 2 expression and high Gleason score late-stage clinical. Furthermore, our results showed high proportion of H3K27me3 marks at RAR beta 2 promoter suggesting a strong involvement of polycomb group proteins in silencing of RAR beta 2 gene in prostate cancer. Consequently, $R A R$ beta 2 may be silenced not only by DNA methylation as previously demonstrated [34].

To provide more evidence that these genes are H3K27me3-dependent silencing, we assessed the levels of RAR beta 2, ER alpha, PGR, and RGMA mRNA using RT-qPCR in PC3, DU145 and LNCaP cell lines after treatment with 3-Dezaneplanocin-A (DZNep), a potent pharmacologic inhibitor of EZH2. DZNep is an $\mathrm{S}$-adenosyl-L-homocysteine hydrolase inhibitor which works across an indirect mechanism blocking S- 


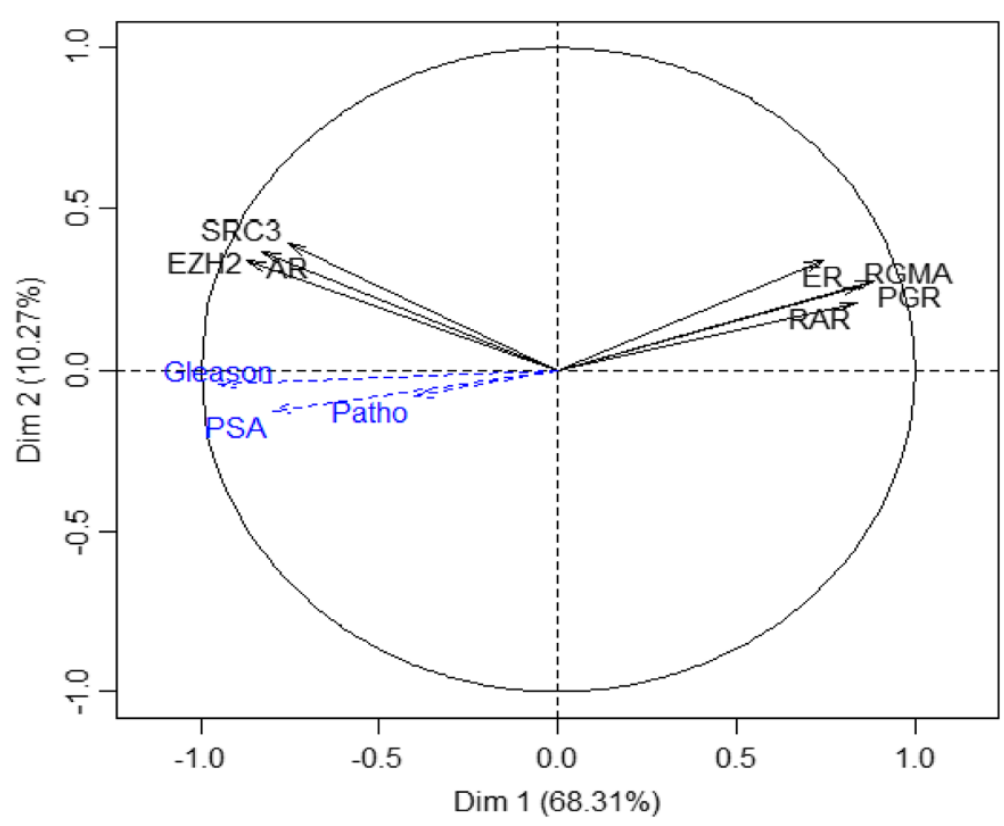

Figure 5 Principal component analysis (PCA) carried out to explore the difference between genes and relationships with clinicopathological parameters. The analysis of gene expression was made by PCA. On the dimension 1 (Dim 1), a clear discrimination can be noted between overexpressed genes (AR, SRC3 and EZH2) and under expressed genes (RAR beta 2, ER alpha, PGR and RGMA). The overexpression of AR, SRC3 and EZH2 gene correlated with PSA level (PSA), clinical stage (patho) and Gleason score (Gleason).

adenosylmethinone-dependent methyltransferases byproduct inhibition. Our results showed that DZNep induced a re-expression of RAR beta 2 suggesting that DNA hypermethylation is not a predominant mechanism of silencing of RAR beta 2. It is also well known that the polycomb complex PRC2 recruits histone deacetylase proteins at the promoter region of target genes and subsequently mediates epigenetic transcriptional repression. However, treatment for prostate cancer cells with SAHA, a potent histone deacetylase (HDAC) inhibitor, results in depletion of $E Z H 2$ and induction of $R A R$ beta 2 in prostate cancer cell lines. Other genes such as $P G R$ and $E R$ alpha were also studied because they have been identified in both normal and prostate cancer tissues. Few studies have reported the involvement of these two receptors in the prostate cancers [35]. But currently, neither mutation nor structural alterations of these receptor genes in prostate cancer have been reported to be responsible for $E R$ alpha or PGR down-regulation. Hopefully, further studies in epigenetics will investigate this issue. However, it was known from previous studies, that the ER alpha promoter is extensively methylated both in prostate cancer cell lines and prostate cancer tissues, leading to $E R$ alpha gene inactivation in prostate cancer [36]. Other studies have shown no significant difference between cancer tissues and normal prostate tissues [4]. We also evidenced a significant increase of H3K27me3 marks on ER alpha gene in prostate tumors compared to normal tissues. Our data added new mechanisms whereby histone methylation could silence $E R$ alpha gene in prostate cancer. Besides, an increase of H3K27me3 marks on $P G R$ gene can explain its downregulation in prostate cancer. These results have been confirmed by Western blotting in prostate tissues.

Our investigations have also shown an increase of H3K27me3 on RGMA gene which would explain the silencing of this gene in prostate cancer. According to the previous studies, results exhibited that, RGMA mRNA was decreased in the prostate cancer tissues compared to normal prostate tissues [10]. However, the mechanisms involved in this regulation of prostate cancer cells are still unknown. In PC3, DU145 and LNCaP cell lines, we found reactivation of $R G M A$ expression after DZNep treatment supporting the hypothesis that $R G M A$ is silenced by EZH2. In order to compare DZNep to other epigenetics drugs such as SAHA, we also observed reactivation of RGMA expression with SAHA. Surely, HDACs bind $\mathrm{PRC} 2$ complex leading to a series of reactions, including decreasing acetylation of H3K27, favoring its methylation and inhibiting gene expression. SAHA would be expected to counteract this activity, resulting in increased acetylation and gene expression.

It should be noted that H3K27me3 would have no effect on SRC3 expression. Using ChIP-qPCR, there is no significant discrepancy between the cancerous group and the normal group. However, SRC3 was overexpressed in prostate cancer compared to normal tissues. When we 


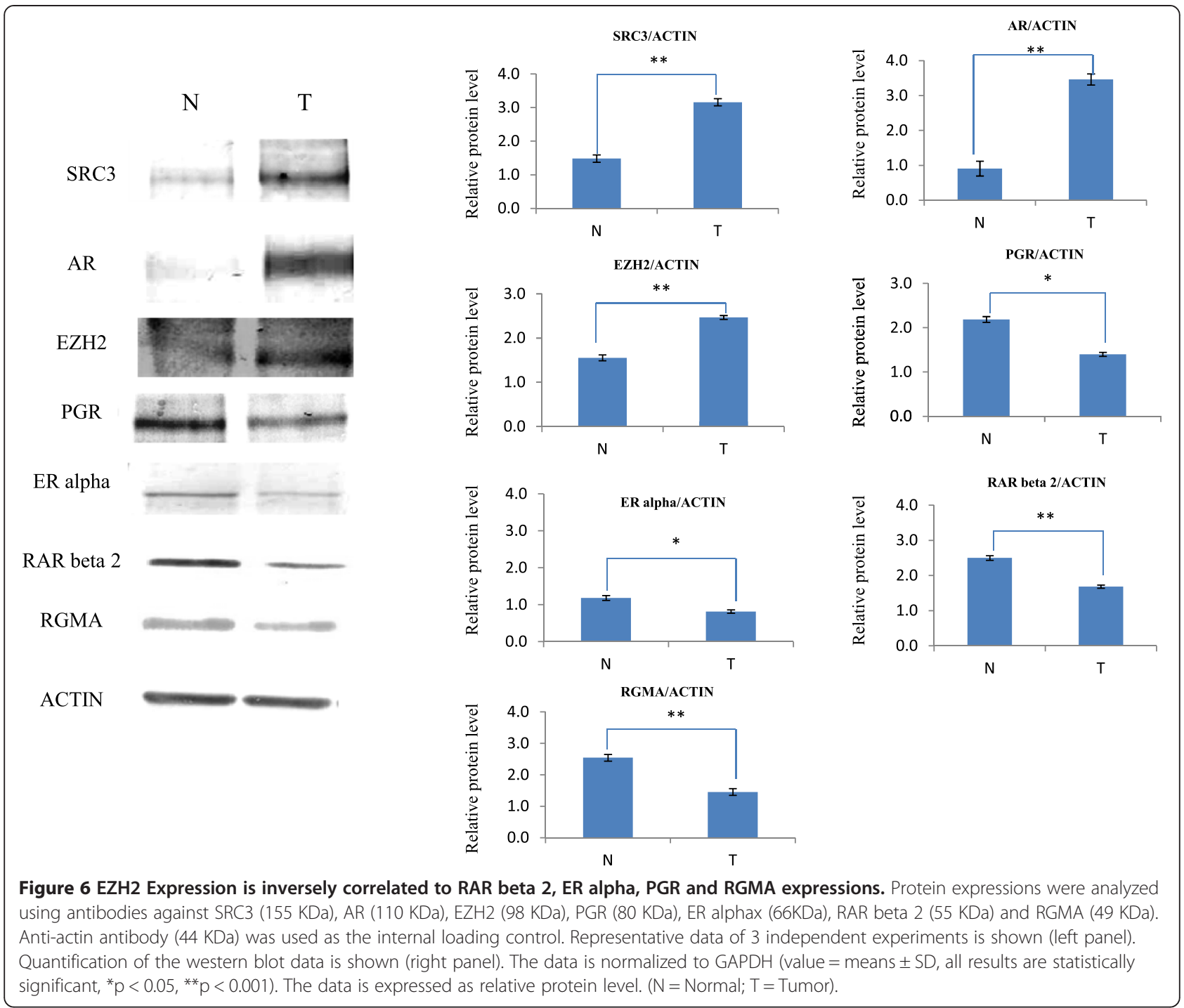

treated prostate cancer cells with SAHA, it was observed an increase of SRC3 expression which is a histone acetyltransferase activity [4].

The AR signalling pathway is a key factor in the development and progression of prostate cancer. DZNep reduces the transcriptional activity of $A R$ in LNCaP cells, suggesting that DZNep negatively regulated $A R$ expression. Furthermore, the initiation of prostate cancer has been linked to activation of AKT pathway due to loss or mutation of PTEN. Additionally over-expression of $A R$ and $E Z H 2$ appeared to be important to promote the progression of prostate cancer. The underlying mechanism remained unknown. Previous studies have shown that, overexpression of $A R$ alone led to a repression of $E Z H 2$ expression while knockdown of $A R$ increased $E Z H 2$ expression in LNCaP cells [37]. This may be due to activation of AKT promoting EZH2 phosphorylation at Serine 21, which down-regulates its methyltransferase activity by blocking EZH2 binding to histone $\mathrm{H} 3$, decreasing H3K27me3 marks leading to de-repressing epigenetic silencing [38].

Moreover, previous studies reported that, SAHA was more efficient in terms of growth inhibition and induction of cell death in androgen-responsive cells [39], suggesting that a component of the activity of SAHA in prostate cancer cells relates to the presence of a functional androgen signalling axis and that HDAC inhibitors decreased AR protein levels without significantly affecting AR protein stability [40,41]. Conversely, in DU145 and PC3 cells, SAHA led to a re-expression of $A R$. Also, there was no significant difference of SAHA activity over $E Z H 2$ expression.

This data suggested that for some genes, the silencing by EZH2 could be an alternative strategy to override to DNA methylation. Certainly, EZH2 was overexpressed in 


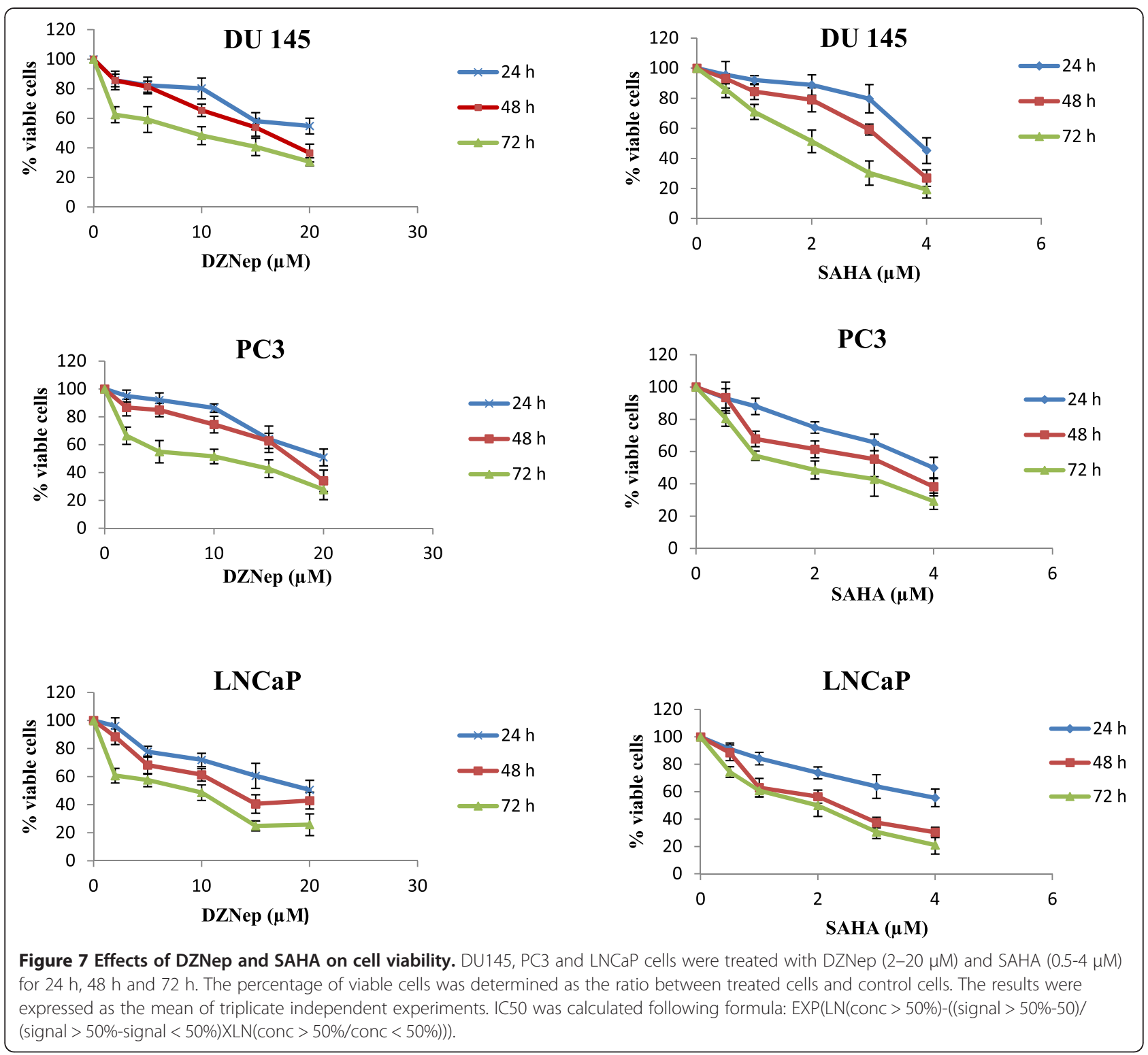

prostate cancer and played a crucial role in several steps of the metastatic process as described in previous studies.

\section{Methods}

\section{Biopsy collection}

The 137 men were hospitalized at the Clermont-Ferrand University Medical Center (France) between 2012 and 2013, and had 12 sextant biopsies [42]. With a letter of consent, patients accepted to give a sample for research. This procedure corresponded to collection of biological samples declared to "Le Ministère de l'Enseignement Supérieur et de la Recherche" with registered number: DC-2008-558. The anatomo-pathological examination diagnosed the stage of cancer development. Each biopsy was stored in a cryotube containing nitrogen solution at $-196^{\circ} \mathrm{C}$ at the Jean
Perrin Center tumorbank, biological resource center (CRB), accredited under No. AC-2013-1882. The clinicopathological characteristics of all the analyzed prostate tissues are listed in Table 4 and Table 5.

\section{Cell lines and culture conditions}

Three human prostate cancer cell lines, including the DU145, PC3, and LNCaP obtained from american type culture collection (ATCC, Manassas, VA, USA) were used. The cells were cultivated in RPMI 1640 medium for LNCaP, in F-12 K medium for PC3, and in eagle's minimum essential medium (EMEM) for DU145 (Gibco, Grand Island, NY, USA). All cultures were supplemented with $10 \%$ heat-inactivated fetal bovine serum (FBS) (Life Technologies, Carlsbad, CA, USA), $1 \%$ glutamin, and $100 \mathrm{U} / \mathrm{ml}$ 


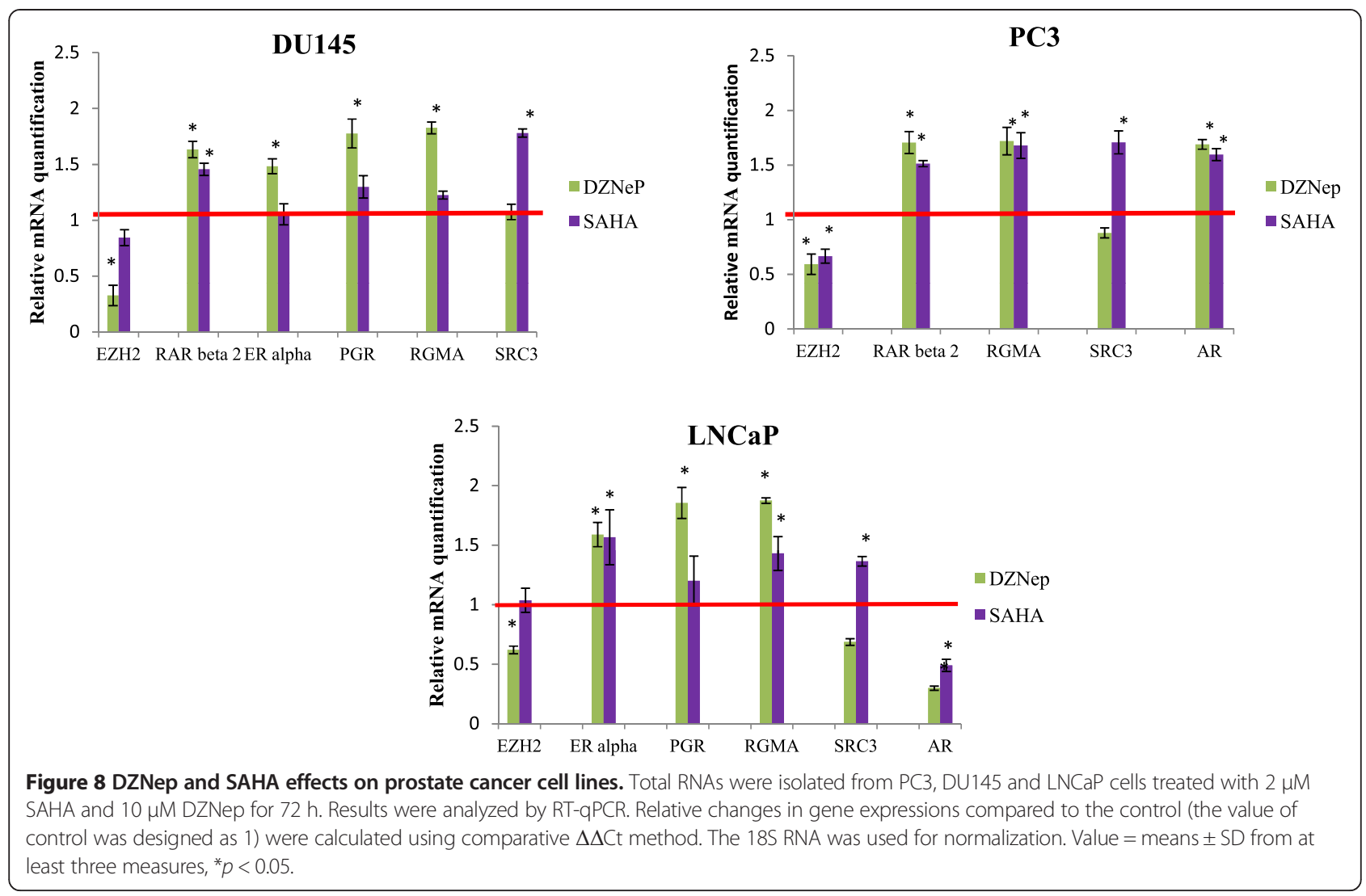

gentamicin (Sigma-Aldrich, St Louis, MO, USA). Cells were maintained as monolayers in an incubator within humidified atmosphere of $95 \%$ air and $5 \% \mathrm{CO}_{2}$ at $37^{\circ} \mathrm{C}$.

\section{Chemical treatments}

To determine the optimal concentration of 3-deaza neplanocin A (DZNep) and suberoylanilide hydroxamic acid (SAHA) (Sigma-Aldrich St. Louis, MO, USA) in prostate cancer cell lines, DZNep and SAHA were dissolved in dimethyl sulphoxide (DMSO, Sigma-Aldrich, St Louis, MO, USA). Final DMSO concentration did not exceeded $0.1 \%$. The same concentration of DMSO was used as a control for these experiments. We measured cell viability using a Scepter ${ }^{\mathrm{rm}} 2.0$ Cell Counter (Millipore, Billerica, MA, USA) in accordance with the manufacturer's standard operating procedures. To identify the demethylating and deacetylating effects of DZNep and SAHA, DU145, LNCaP and PC3 cells were distributed in six-well culture plates at a density of $0.5 \times 10^{5}$ cells per well. After 24 hours, cells were treated with increased doses of DZNep and SAHA using $10 \mu \mathrm{l}$ DMSO for respectively and gradually 24, 48 and 72 hours. After treatments, cells were washed with phosphate buffered saline (PBS, Life Technologies, Carlsbad, CA, USA), trypsinized, harvested and the number of viable cells was counted. Viable cells were presented as a percentage of the untreated cells control and $\mathrm{IC}_{50}$ is done by linear interpolation between concentrations just above and beneath 50\% inhibition in the response dose curve.

\section{Chromatin extraction and shearing}

Chromatin extraction was carried out on carcinoma and normal prostate samples (Table 4). Tissues were treated with $1 \%$ formaldehyde for $15 \mathrm{~min}$ to crosslink histone to DNA. The crosslinking reaction was stopped with $0.125 \mathrm{M}$ fresh glycine for $5 \mathrm{~min}$. After washing by cold PBS, the samples were grinded with TissueRuptor ${ }^{\bullet}$ (Qiagen, Hilden, Germany) until getting a homogeneous suspension. The lysate was centrifuged at $4000 \mathrm{~g}$ for $10 \mathrm{~min}$ at $4^{\circ} \mathrm{C}$ and the cell pellet was re-suspended in lysis buffer ( $5 \mathrm{mM}$ PIPES pH 8; 85 mM KCL; 0.5\% IGEPAL, protease inhibitor cocktail) and incubated in ice for $15 \mathrm{~min}$. Then, nuclei were centrifuged at $4000 \mathrm{~g}$ for $10 \mathrm{~min}$ and the pellet was resuspended in shearing buffer (Diagenode, Seraing, Belgium), incubated in ice for $5 \mathrm{~min}$ and sonicated (Bioruptor $^{\mathrm{Tm}}$ sonicator, Diagenode) for $40 \mathrm{~min}$. This produced chromatin fragments of 100 to 600 bp suitable for ChIP assays as they cover 2 to 3 nucleosomes. Immediately after sonication, the samples were cleaned by centrifugation at $4000 \mathrm{~g}$ for $10 \mathrm{~min}$ at $4^{\circ} \mathrm{C}$ and supernatants containing the sheared chromatin were transferred into new tubes. Sonicated chromatin was used for DNA 
Table 4 Summary of clinicopathological parameters in prostate samples for ChIP-qPCR

\begin{tabular}{|c|c|c|}
\hline CASES & $\mathrm{TT}$ & NT \\
\hline Total cases $(n=65)$ & 32 & 33 \\
\hline \multicolumn{3}{|l|}{ Age at diagnosis (years) } \\
\hline$<49$ & 0 & 1 \\
\hline $50-59$ & 6 & 10 \\
\hline $60-69$ & 17 & 17 \\
\hline$>70$ & 9 & 5 \\
\hline \multicolumn{3}{|l|}{ PSA baseline (ng/mL) } \\
\hline$<4$ & 0 & 4 \\
\hline $4-10$ & 14 & 23 \\
\hline $10-20$ & 8 & 4 \\
\hline$>20$ & 10 & 2 \\
\hline \multicolumn{3}{|l|}{ Clinical stage } \\
\hline T1c & 17 & - \\
\hline $\mathrm{T} 2 \mathrm{a}$ & 7 & - \\
\hline $\mathrm{T} 2 \mathrm{~b}$ & 6 & - \\
\hline $\mathrm{T} 2 \mathrm{C}$ & 1 & - \\
\hline T3 & 1 & - \\
\hline \multicolumn{3}{|l|}{ Gleason score } \\
\hline$\leq 7$ & 19 & - \\
\hline$>7$ & 13 & - \\
\hline
\end{tabular}

T: tumoral tissues; NT: normal tissues; PSA: prostate-specific antigen.

extraction (sonication optimization experiments; data not shown) or for chromatin immunoprecipitation (ChIP) assay.

\section{Chromatin immunoprecipitation}

ChIP was performed using auto ChIP kit (Diagenode) according to manufacturer's instructions. Anti-human H3K27me3 (pAb-069-050, Diagenode) produced in rabbit and also non-immune rabbit IgG (negative control) (kch504-250, Diagenode) were used. The ChIP was carried out by $\mathrm{SX}-8 \mathrm{X}^{\circ}$ Automated System (Diagenode) according to the protocol provided by the manufacturer. The reaction was incubated for $2 \mathrm{~h}$ for antibody coating with protein A-coated magnetic beads, then for $10 \mathrm{~h}$ at $4^{\circ} \mathrm{C}$ for immunoprecipitation reaction. Later on, $1 \mu \mathrm{L}$ of proteinase $\mathrm{K}$ was added and the reverse cross-linking was performed for $45 \mathrm{~min}$ at $65^{\circ} \mathrm{C}$. The immunoprecipitated DNA and input samples were analyzed by real-time qPCR.

\section{Quantitative real-time PCR}

Real-time PCR was performed in triplicate on a $25 \mu \mathrm{l}$ reaction containing 1X TaqMan Universal PCR Master Mix (Applied Biosystems) and $400 \mathrm{nM}$ of each of forward and reverse primers (Sigma-Aldrich), $250 \mathrm{nM}$ of probe (Sigma-Aldrich) and $4.25 \mu \mathrm{L}$ of water. TaqMan qPCRs were then carried out for $E Z H 2$, RAR beta 2, ER
Table 5 Summary of clinicopathological parameters in prostate samples for RT-qPCR

\begin{tabular}{ccc}
\hline CASES & TT & N \\
\hline Total cases $(n=72)$ & 34 & 38 \\
Age at diagnosis (years) & & \\
$<49$ & 0 & 0 \\
$50-59$ & 2 & 10 \\
$60-69$ & 11 & 2 \\
$>70$ & 21 & 7
\end{tabular}

PSA baseline $(\mathrm{ng} / \mathrm{mL})$

$<4$

4-10

12

$10-20$

$>20$

1425

$9-11$

Clinical stage

T1C 13

T2a 2

T2b 10

$\mathrm{T} 2 \mathrm{C}-2$

T3 6

T4

Gleason score

$\leq 7 \quad 19$

$>7$

15

$\Pi$ T: tumoral tissues; NT: normal tissues; PSA: prostate-specific antigen.

alpha, PGR, RGMA, and SRC3 genes. The oligonucleotide primers and probes are shown in Table 6. The efficiency of chromatin immunoprecipitation of particular genomic locus was calculated from qPCR data and reported as a percentage of starting material: \% (ChIP/total input).

$$
\begin{gathered}
\%(\mathrm{ChIP} / \text { total input })=2^{\wedge}[(\mathrm{Ct}(\text { input })-\log (\times \%) / \log 2)-\mathrm{Ct}(\mathrm{ChIP})] \\
\times 100 \%
\end{gathered}
$$

Ct (input) and Ct (ChIP) are threshold values obtained from exponential phase of qPCR for the immunoprecipated DNA sample and input sample respectively. $\log (\mathrm{X} \%) / \log 2$ accounted for the dilution $1 / \mathrm{X}$ of the input.

\section{Reverse transcription and qPCR}

One microgram of mRNA from each sample was reversely transcribed in a total volume of $15 \mu \mathrm{l}$ using first strand cDNA synthesis kit (GE Healthcare Life Science, Piscataway, NJ, USA) according to the manufacturer's instructions. The resulting cDNA was then quantified with the TaqMan method (ABI Prism 7900 HT, Applied Biosystems). Duplex PCR was carried out in 96-well plate using $10 \mathrm{ng}$ of cDNA in a total volume of $25 \mu \mathrm{l}$ containing 
Table 6 Forward, reverse primers and probes used for ChIP-qPCR for amplification of the gene promoter region

\begin{tabular}{|c|c|c|}
\hline Genes & qPCR primer sequences & qPCR MGB Probes (Taqman $\left.{ }^{\circledast}\right)$ \\
\hline \multirow[t]{2}{*}{$E Z H 2$} & Forward AGTGCAATGGCGCGATCT & TCACCGCAACCTC \\
\hline & Reverse GAGGCATGAGAATCGCTTGAA & \\
\hline \multirow[t]{2}{*}{ RAR beta 2} & Forward GCACGTAGGCTGTTGGTCTIT & CCAGCCCCGAATC \\
\hline & Reversre GCTGGCTTGTCTGTCATAATTCA & \\
\hline \multirow[t]{2}{*}{$P G R$} & Forward GAGCCGCGTGTCACTAAATTG & CGTCGCAGCCGCA \\
\hline & Reverse TCACAAGTCCGGCACTTGAG & \\
\hline \multirow[t]{2}{*}{ ER alpha } & Forward CCCTGACATTGGCTTAAACATCA & TCCAGGCACAACTC \\
\hline & Reverse TCTTTGGGATCGCTCCAAAT & \\
\hline \multirow[t]{2}{*}{$R G M A$} & Forward CTGCCAGGTCGGGAGTGT & AGAGGAGCAAGTTTG \\
\hline & Reverse CACAGCCATAGGGCCTTCTC & \\
\hline \multirow[t]{2}{*}{$S R C 3$} & Forward AAAATTAAGGGCAGGGCTAGGA & TCCGGATCCCGAGGGAGCTCC \\
\hline & Reverse GTGCGGCCGCTTTCG & \\
\hline
\end{tabular}

12.5 $\mu$ l TaqMan Gene Expression Master Mix (2X) (4369016, Applied Biosystem), 200nM of EZH2, RAR beta2, ER alpha, PGR, RGMA, SRC3, and AR Applied Biosystems assays-on-demand: EZH2 (Hs01016789_m1), RARbeta2 (Hs00977140_m1), ER alpha (Hs00174860_m1), PGR (Hs01556702_m1), RGMA (Hs00297192_m1), SRC3 (Hs01105251_m1) and $A R$ (Hs00171172_m1), $10 \mu \mathrm{M} 18 S$ rRNA primers and $5 \mu \mathrm{M} 18 S$ rRNA TaqMan probe. $18 S$ primers and TaqMan probe were purchased as follows: forward: 5'-CGG CTA CCA CAT CCA AGG AA-3', reverse: 5'-GCT GGA ATT ACC GCG GCT-3', probe: 5'-TGC TGG CAC CAG ACT TGC CCT C-3' (VIC). Data were collected using an AB Prism 7900 Sequence Detector System (Applied Biosystem) for 45 cycles $\left(50^{\circ} \mathrm{C}\right.$ during $2 \mathrm{~min}, 95^{\circ} \mathrm{C}$ for $10 \mathrm{~min}, 95^{\circ} \mathrm{C}$ for $15 \mathrm{~s}$ and $60^{\circ} \mathrm{C}$ for $1 \mathrm{~min}$ ). Samples were normalized to $18 S$ rRNA level. The comparative cycle threshold (CT) method $\left(2^{-\Delta \Delta C t}\right)$ was used to calculate the relative gene expression. All data were generated at least in triplicate and expressed as mean \pm SD. Genes were considered significantly expressed and their transcript measurable if their corresponding $\mathrm{Ct}$ value was less than or equal to 35.

\section{Western-blotting}

Total protein extractions were performed using RIPA buffer (Sigma-Aldrich) according to the manufacturer's instructions. Protein concentration was assayed using the Bradford method (Bio-Rad, Hercules, CA, USA) and equal amount of proteins $(25 \mu \mathrm{g})$ was separated by electrophoresis on 4-12\% SDS-PAGE gels (Bio-Rad Laboratories,Hercules, CA, USA) and transferred to polyvinylidene fluoride membranes (GE healthcare). Membranes were blocked with $5 \%$ nonfat milk in $0.1 \%$ TBS- tween for 1 hour at room temperature, washed, and incubated overnight at $4^{\circ} \mathrm{C}$ with primary antibodies in $1 \%$ nonfat milk and $0.1 \%$ TBS-tween. Primary antibodies used were as follow: anti-EZH2 (1:500, pAb-039-050, Diagenode), antiRAR beta 2 (1:500, GTX12011, GeneTex), anti-ER alpha (1:250, AC-066-100, Diagenode), anti-PGR (1:250, PAB1 2723, Abnova), anti-RGMA (1:250, H00056963-M01, Abnova), anti-SRC3 (1:750, MAB7999, Abnova, Walnut, CA, USA), anti-AR (1:1000, GTX73078, GeneTex, Irvine, CA, USA) and anti- $\beta$ Actin (1 :4000, CP01, Millipore). A secondary antibody consisted of anti-mouse IgG or antirabbit IgG alkaline phosphatase conjugates (1:2000, S372B and S373B respectively, Promega, Madison, WI, USA). After final washes, blots were developed using Western Blue Stabilized substrate for alkaline phosphate (201608-26, Promega).

\section{Statistical analysis \\ Analysis of variance}

All statistical analysis were performed using R 3.0.1 software [43] and the statistical packages agricolae [44], $\mathrm{HH}$ [45] and multcomp [46]. All the data obtained were statistically analyzed with a one-way ANOVA to test the level of statistical significance of different groups on H3K27me3 levels and relationships between clinicalpathological parameters on different genes. Post-hoc procedures were used when the F-test was significant $(\mathrm{p}<0.05)$. Multiple comparisons among means were examined by a Tukey's Post Hoc test. The level of statistical significance was set at $\mathrm{p}<0.05$.

\section{Principal Component Analysis}

The major aim of Principal Component Analysis (PCA) is the orderly simplification of a large number of intercorrelated measures to a few uncorrelated representative constructs or factors [47]. In this study, a small number of linear combinations (called principal components) are derived from a set of variables (genes) measured on several 
observations (patients) that retain as much as possible of the information about the original variables. This goal typically overrides in empirical research its secondary aim, which is interpretation of the principal components. To a large extent, the interpretation of principal components is generally guided by the degree to which each variable is associated with a particular component [47]. The main outputs of the principal component analysis are the variances of the principal components and two plots: the projections of the original variables; and the observations onto the plane made by the two first principal components. In the first plot, as all variables are normalized (mean equal to zero and variance equal to 1), the distances between the projections of the variables and the centre are equal to 1 , meaning that the projections near the circumference of the circle belong to the plane of the two first principal components, and the projections near the centre do not belong to the plane as they appear to be orthogonal. Those variables, found to be most closely related to a component in question are used as a guide for its interpretation. Principal Component Analysis was performed using the statistical package FactoMineR [48].

\section{Discriminant Analysis}

Discriminant analysis is a powerful descriptive and classificatory technique to first describe characteristics that are specific to distinct groups (called descriptive discriminant analysis) and secondly classify cases (i.e., patients, subjects, participants) into pre-existing groups based on similarities between different cases that belong to a specific group [49]. Discriminant analysis can answer some questions that include: (a) in which ways do various groups in a study differ? (b) What differences exist between and among the number of groups on a specific set of variables? (c) Which continuous variables best characterize each group, or, which continuous variables are not characteristic of the individual groups? (d) Given the results of a multivariate analysis of variance indicating that group differences exist in the data, what specific variables best account for these differences? [49]. Given two or more groups or populations and a set of associated variables one often wants to locate a subset of the variables and associated functions of the subset that leads to maximum separation among the centroids of the groups. The goals of a discriminant analysis are about constructing a set of discriminants that may be used to describe or characterize group separation based upon a reduced set of variables, to analyze the contribution of the original variables to the separation, and to evaluate the degree of separation. To test the contribution of each variable, Wilks' lambda is used in an ANOVA [48] test of mean differences in discriminant analysis, so that the smaller the lambda for an independent variable, the more that variable contributes to the discriminant function. Lambda varies from 0 to 1 , with 0 representing group means differ and 1 meaning that all group means are the same. The F test of Wilks' lambda shows which variables contributions are significant. Discriminant Analysis was performed using the statistical package rrcov [50].

\section{Conclusion}

Based on the overall results, we believe in a direct role of EZH2 in silencing of RAR beta 2, ER alpha, PGR, and $R G M A$ genes via $\mathrm{H} 3 \mathrm{~K} 27 \mathrm{me} 3$ mark in prostate cancer and therefore indicates adverse prognosis. Treatment with DZNep led to the reactivation of genes silenced by epigenetic mechanisms in prostate cancer. In view of these results, we demonstrated that histone modifications contributed to the onset and progression of prostate cancer and H3K27me3 would be considered as a promising biomarker. The identification of these molecular markers will be used to supplement clinical markers and will allow us to better predict cancer progression.

\section{Competing interests}

The authors declare that they have no competing interests.

\section{Authors' contributions}

$D B G, L G, J P B, Y J B$, FPL conceived and designed the research. $M N, G J, A D$, $\mathrm{SKC}, \mathrm{MD}$ performed the experiments. MN, LG, DBG analyzed the data. AL performed the statistical analysis. MN, DBG wrote the paper. JLK carried out anatomopathological examination. All authors read and approved the final manuscript.

\section{Acknowledgments}

The present research was supported by grant from "La Ligue contre le Cancer - Comités de la région Auvergne". Aslihan Dagdemir received a grant from Protema Saglik Hizm A.S (Istanbul, Turkey). Seher Karsli-Ceppioglu was supported by the Scientific and Technology Research Council of Turkey (TUBITAK-2219) project grants. The authors thank Nicolas Sonnier for technical assistance. We would like to gratefully acknowledge all staff members of the Centre Jean Perrin Biological Resource Center (CRB) accredited under No.

AC-2013-1882 for their help in centralizing and managing biological collections.

\section{Author details}

'Department of Oncogenetics, Centre Jean Perrin, CBRV, 28 place Henri Dunant, BP 38, 63001 Clermont-Ferrand, France. 'EA 4677 "ERTICA", University of Auvergne, 28 place Henri Dunant, BP 38, 63001 Clermont-Ferrand, France. ${ }^{3}$ University Blaise Pascal, Institut Pascal UMR 6602 CNRS/UBP, 24 Avenue des Landais, Aubiere, France. ${ }^{4}$ Department of Anatomo-pathology, Gabriel Montpied Hospital, 58 rue Montalembert, 63001 Clermont-Ferrand, France. ${ }^{5}$ Department of Urology, Gabriel Montpied Hospital, 58 rue Montalembert, 63001 Clermont-Ferrand, France.

Received: 20 August 2014 Accepted: 16 December 2014 Published: 23 December 2014

\section{References}

1. Jemal A, Bray F, Center MM, Ferlay J, Ward E, Forman D: Global cancer statistics. CA Cancer J Clin 2011, 61:69-90.

2. Majumdar S, Buckles E, Estrada J, Koochekpour S: Aberrant DNA methylation and prostate cancer. Curr Genomics 2011, 12:486-505.

3. Adjakly M, Bosviel R, Rabiau N, Boiteux J-P, Bignon Y-J, Guy L, Bernard-Gallon D: DNA methylation and soy phytoestrogens: quantitative study in DU-145 and PC-3 human prostate cancer cell lines. Epigenomics 2011, 3:795-803.

4. Dagdemir A, Durif J, Ngollo M, Bignon Y-J, Bernard-Gallon D: Histone lysine trimethylation or acetylation can be modulated by phytoestrogen, estrogen or anti-HDAC in breast cancer cell lines. Epigenomics 2013, 5:51-63.

5. Rabiau N, Trraf H-K, Adjakly M, Bosviel R, Guy L, Fontana L, Bignon Y-J, Bernard-Gallon DJ: miRNAs differentially expressed in prostate cancer cell lines after soy treatment. In Vivo 2011, 25:917-921. 
6. You JS, Jones PA: Cancer genetics and epigenetics: two sides of the same coin? Cancer Cell 2012, 22:9-20.

7. Chen Z, Wang L, Wang Q, Li W: Histone modifications and chromatin organization in prostate cancer. Epigenomics 2010, 2:551-560.

8. Kondo Y, Shen L, Cheng AS, Ahmed S, Boumber Y, Charo C, Yamochi T, Urano T, Furukawa K, Kwabi-Addo B, Gold DL, Sekido Y, Huang TH-M, Issa J-PJ: Gene silencing in cancer by histone H3 lysine 27 trimethylation independent of promoter DNA methylation. Nat Genet 2008, 40:741-750.

9. Kerppola TK: Polycomb group complexes-many combinations, many functions. Trends Cell Biol 2009, 19:692-704.

10. Richly H, Aloia L, Di Croce L: Roles of the Polycomb group proteins in stem cells and cancer. Cell Death Dis 2011, 2:e204.

11. Cavalli G: Molecular biology. EZH2 goes solo. Science 2012, 338:1430-1431.

12. Varambally S, Cao Q, Mani R-S, Shankar S, Wang X, Ateeq B, Laxman B, Cao X, Jing X, Ramnarayanan K, Brenner JC, Yu J, Kim JH, Han B, Tan P, Kumar-Sinha C, Lonigro RJ, Palanisamy N, Maher CA, Chinnaiyan AM: Genomic loss of microRNA-101 leads to overexpression of histone methyltransferase EZH2 in cancer. Science 2008, 322:1695-1699

13. Koh CM, Iwata T, Zheng Q, Bethel C, Yegnasubramanian S, De Marzo AM: Myc enforces overexpression of EZH2 in early prostatic neoplasia via transcriptional and post-transcriptional mechanisms. Oncotarget 2011, 2:669-683.

14. Kwabi-Addo B, Wang S, Chung W, Jelinek J, Patierno SR, Wang B-D, Andrawis R, Lee NH, Apprey V, Issa J-P, Ittmann M: Identification of differentially methylated genes in normal prostate tissues from African American and Caucasian men. Clin Cancer Res Off J Am Assoc Cancer Res 2010, 16:3539-3547.

15. Moison C, Senamaud-Beaufort C, Fourrière L, Champion C, Ceccaldi A, Lacomme S, Daunay A, Tost J, Arimondo PB, Guieysse-Peugeot A-L: DNA methylation associated with polycomb repression in retinoic acid receptor $\beta$ silencing. FASEB J Off Publ Fed Am Soc Exp Biol 2013, 27:1468-1478.

16. Nishimori H, Ehata S, Suzuki HI, Katsuno Y, Miyazono K. Prostate cancer cells and bone stromal cells mutually interact with each other through bone morphogenetic protein-mediated signals. J Biol Chem 2012, 287:20037-20046.

17. Li J, Ye L, Kynaston HG, Jiang WG: Repulsive guidance molecules, novel bone morphogenetic protein co-receptors, are key regulators of the growth and aggressiveness of prostate cancer cells. Int J Oncol 2012, 40:544-550.

18. Latil A, Bièche I, Vidaud D, Lidereau R, Berthon P, Cussenot O, Vidaud M: Evaluation of androgen, estrogen (ER alpha and ER beta), and progesterone receptor expression in human prostate cancer by real-time quantitative reverse transcription-polymerase chain reaction assays. Cancer Res 2001, 61:1919-1926.

19. Walton TJ, Li G, McCulloch TA, Seth R, Powe DG, Bishop MC, Rees RC: Quantitative RT-PCR analysis of estrogen receptor gene expression in laser microdissected prostate cancer tissue. The Prostate 2009, 69:810-819.

20. Zhou H-J, Yan J, Luo W, Ayala G, Lin S-H, Erdem H, Ittmann M, Tsai SY, Tsai $\mathrm{M}-\mathrm{J}$ : SRC-3 is required for prostate cancer cell proliferation and survival. Cancer Res 2005, 65:7976-7983.

21. Feinberg AP: Phenotypic plasticity and the epigenetics of human disease. Nature 2007, 447:433-440.

22. Rabiau N, Thiam MO, Satih S, Guy L, Kemeny J-L, Boiteux J-P, Fontana L, Bignon Y-J, Bernard-Gallon D: Methylation analysis of BRCA1, RASSF1, GSTP1 and EPHB2 promoters in prostate biopsies according to different degrees of malignancy. In Vivo 2009, 23:387-391.

23. Vardi A, Bosviel R, Rabiau N, Adjakly M, Satih S, Dechelotte P, Boiteux J-P, Fontana L, Bignon Y-J, Guy L, Bernard-Gallon DJ: Soy phytoestrogens modify DNA methylation of GSTP1, RASSF1A, EPH2 and BRCA1 promoter in prostate cancer cells. In Vivo 2010, 24:393-400.

24. Seligson DB, Horvath S, Shi T, Yu H, Tze S, Grunstein M, Kurdistani SK: Global histone modification patterns predict risk of prostate cancer recurrence. Nature 2005, 435:1262-1266

25. Ngollo M, Dagdemir A, Judes G, Kemeny J-L, Penault-Llorca F, Boiteux J-P, Lebert A, Bignon Y-J, Guy L, Bernard-Gallon D: Epigenetics of Prostate Cancer: Distribution of Histone H3K27me3 Biomarkers in Peri-Tumoral Tissue. Omics 2014, 18:207-209.

26. Steiner I, Jung K, Schatz P, Horns T, Wittschieber D, Lein M, Dietel M, Erbersdobler A: Gene promoter methylation and its potential relevance in early prostate cancer diagnosis. Pathobiol J Immunopathol Mol Cell Biol 2010, 77:260-266.

27. Varambally S, Dhanasekaran SM, Zhou M, Barrette TR, Kumar-Sinha C, Sanda MG, Ghosh D, Pienta KJ, Sewalt RGAB, Otte AP, Rubin MA, Chinnaiyan AM: The polycomb group protein $\mathrm{EZH} 2$ is involved in progression of prostate cancer. Nature 2002, 419:624-629.

28. Yang YA, Yu J: EZH2, an epigenetic driver of prostate cancer. Protein Cell 2013, $4: 331-341$
29. Rabiau N, Déchelotte P, Adjakly M, Kemeny J-L, Guy L, Boiteux J-P, Kwiatkowski F, Bignon Y-J, Bernard-Gallon D: BRCA1, BRCA2, AR and IGF-I expression in prostate cancer: correlation between RT-qPCR and immunohistochemical detection. Oncol Rep 2011, 26:695-702.

30. Prins GS, Korach KS: The role of estrogens and estrogen receptors in normal prostate growth and disease. Steroids 2008, 73:233-244.

31. Rabiau N, Dantal Y, Guy L, Ngollo M, Dagdemir A, Kemeny J-L, Terris B, Vieillefond A, Boiteux J-P, Bignon Y-J, Bernard-Gallon D: Gene panel model predictive of outcome in patients with prostate cancer. Omics J Integr Biol 2013, 17:407-413.

32. Li VSW, Yuen ST, Chan TL, Yan HHN, Law WL, Yeung BHY, Chan ASY, Tsui $W Y$, So $S$, Chen $X$, Leung SY: Frequent inactivation of axon guidance molecule RGMA in human colon cancer through genetic and epigenetic mechanisms. Gastroenterology 2009, 137:176-187.

33. Nakayama T, Watanabe M, Yamanaka M, Hirokawa Y, Suzuki H, Ito H, Yatani $R$, Shiraishi $T$ : The role of epigenetic modifications in retinoic acid receptor beta2 gene expression in human prostate cancers. Lab Investig J Tech Methods Pathol 2001, 81:1049-1057.

34. Maruyama R, Toyooka S, Toyooka KO, Virmani AK, Zöchbauer-Müller S, Farinas AJ, Minna JD, McConnell J, Frenkel EP, Gazdar AF: Aberrant promoter methylation profile of prostate cancers and its relationship to clinicopathological features. Clin Cancer Res 2002, 8:514-519.

35. Lau KM, LaSpina M, Long J, Ho SM: Expression of estrogen receptor (ER)-alpha and ER-beta in normal and malignant prostatic epithelial cells: regulation by methylation and involvement in growth regulation. Cancer Res 2000, 60:3175-3182.

36. Daniels G, Gellert LL, Melamed J, Hatcher D, Li Y, Wei J, Wang J, Lee P: Decreased expression of stromal estrogen receptor $a$ and $\beta$ in prostate cancer. Am J Transl Res 2014, 6:140-146.

37. Cai H, Memarzadeh S, Stoyanova T, Beharry Z, Kraft AS, Witte ON: Collaboration of Kras and androgen receptor signaling stimulates EZH2 expression and tumor-propagating cells in prostate cancer. Cancer Res 2012, 72:4672-4681.

38. Cha T-L, Zhou BP, Xia W, Wu Y, Yang C-C, Chen C-T, Ping B, Otte AP, Hung $\mathrm{M}-\mathrm{C}$ : Akt-mediated phosphorylation of $\mathrm{EZH} 2$ suppresses methylation of lysine 27 in histone H3. Science 2005, 310:306-310.

39. Marrocco DL, Tilley WD, Bianco-Miotto T, Evdokiou A, Scher HI, Rifkind RA, Marks PA, Richon VM, Butler LM: Suberoylanilide hydroxamic acid (vorinostat) represses androgen receptor expression and acts synergistically with an androgen receptor antagonist to inhibit prostate cancer cell proliferation. Mol Cancer Ther 2007, 6:51-60.

40. Chen L, Meng S, Wang H, Bali P, Bai W, Li B, Atadja P, Bhalla KN, Wu J: Chemical ablation of androgen receptor in prostate cancer cells by the histone deacetylase inhibitor LAQ824. Mol Cancer Ther 2005, 4:1311-1319.

41. Welsbie DS, Xu J, Chen Y, Borsu L, Scher HI, Rosen N, Sawyers CL: Histone deacetylases are required for androgen receptor function in hormonesensitive and castrate-resistant prostate cancer. Cancer Res 2009, 69:958-966.

42. Bjurlin MA, Taneja SS: Standards for prostate biopsy. Curr Opin Urol 2014, 24:155-161

43. R Development Core Team: $R$ : A language and environment for statistical computing. Vienna, Austria: R Foundation for Statistical Computing; 2013.

44. Mendiburu F: agricolae: Statistical Procedures for Agricultural Research. $R$ package version 1.1.4. 2013. http://CRAN.R-project.org/package=agricolae.

45. Heiberger RM: HH:Statistical Analysis and Data Display. New York, USA: Springer Science; 2013

46. Torsten H, Bretz F, Westfall P, Heiberger RM: Multcomp: Simultaneous Inference in General Parametric Models. Biometrical Journal 2014, 50:346-363.

47. Raykov T, Marcoulides GA: An introduction to applied multivariate analysis. New York, USA: Routledge; 2008.

48. Husson F, Josse J, Le S, Mazt J: FactoMineT: Multivariate Exploratory Data Analysis and Data Mining with R. R package version 1.25. Journal of statistical Software 2013, 25:1-18.

49. Brown TA, Wicker LR: Discriminant Analysis in Handbook of Applied Multivariate Statistics and Mathematical Modeling. Edited by Tinsley HEA, Brown SD. California, USA: Elsevier Science \& Technology Books; 2000.

50. Todorov V, Filzmoser P: $\operatorname{rrcov}()$ an Object-Oriented Framework for Robust Multivariate Analysis. Journal of Statistical Software 2009, 32(3):1-47.

doi:10.1186/1471-2407-14-994

Cite this article as: Ngollo et al:: The association between Histone 3 Lysine 27 Trimethylation (H3K27me3) and prostate cancer: relationship with clinicopathological parameters. BMC Cancer 2014 14:994. 